\title{
Lo público en los procesos comunitarios de los pueblos indígenas en México
}

\author{
Enrique David Gallardo García \\ Instituto Tecnológico y de Estudios Superiores de Monterrey, Monterrey, México. \\ Email: ed_gall@hotmail.com
}

\begin{abstract}
Resumen: En los pueblos indígenas de México existen mecanismos de toma de decisión y participación que contribuyen al logro del bienestar común. Estos procesos constituyen parte del espacio público para resolver sus problemas y a través de ellos se reafirman la pertenencia e identidad que fortalecen las relaciones sociales, políticas, económicas y culturales de los miembros de la comunidad. La forma en que se manifiesta esta reafirmación es por medio de la participación en el trabajo comunitario, el sistema de cargos y las asambleas comunitarias. Sin embargo, en los últimos años, con la intervención de las políticas públicas de los distintos órdenes de gobierno y la inclusión de estos pueblos en los procesos políticos, en la búsqueda de una mayor participación ciudadana y el ejercicio de sus derechos civiles en un contexto democrático, han modificado las reglas de convivencia afectando estos mecanismos que son la base de la estructura comunitaria.
\end{abstract}

Palabras clave: procesos comunitarios, espacio público, indígenas, México.

\section{The public realm in community processes of indigenous inhabitants in Mexico}

Abstract: Among indigenous communities of Mexico, there exist many important mechanisms for undertaking relevant decisions and actions to achieve common welfare. These processes are part of the public realm that serve to the purpose of solving problems, and thus contribute to reaffirm identity and communal membership which also strengthens political, economic, social and cultural relations among their members. Participation in community work, assembly and structure of charges are the way that this reaffirmation is expressed. However, in recent years, with the intervention of public policies implemented by different levels of government, and the inclusion of indigenous inhabitants in politic processes in the search for a wider citizen participation and the exercise of their civil rights in a democratic context, the social rules of these indigenous people are being modified affecting their social mechanisms which are the bases of their community structure.

Key words: community processes, public space, indigenous, México.

\section{O público nos processos comunitários dos povos indígenas no México}

Resumo: Nos povos indígenas do México, existem mecanismos para a tomada de decisão e participação que contribuam para alcançar o bem comum. Estes processos fazem parte do espaço público para resolver os seus problemas e, através deles reafirmar a pertença e identidade que fortalecem direitos sociais, políticos, econômicos e culturais dos membros da comunidade. A maneira em que esta afirmação se manifesta através da participação em trabalho comunitário, o sistema de cargos e assembléias comunitárias. No entanto, nos últimos anos, com a participação das políticas públicas dos diversos níveis de governo ea inclusão dos povos indígenas nos processos políticos na busca de maior participação dos cidadãos eo exercício de seus direitos civis em um contexto democracia, mudaram as regras de conduta que afetam esses mecanismos que fundamentam a estrutura da comunidade.

Palavras-chave: processos comunitários, espaço público, indígenas, México

$$
* * *
$$

\section{Introducción}

Más que hablar de lo público como un espacio de disputa, al interior de los pueblos indígenas lo público se manifiesta en mecanismos de convergencia y de discusión para la toma de decisiones. Sin embargo, gran parte de estos mecanismos se han visto afectados por la influencia de procesos políticos distintos a su perspectiva, donde se antepone el ejercicio pleno de los derechos individuales a los derechos colectivos que se privilegian en estos pueblos. 
Los Estados modernos han buscado el modo de adaptar sus formas de gobernar a las situaciones actuales, sin embargo hay elementos que se conservan a través de diferentes períodos y que se han convertido en reglas que no pueden faltar en el ejercicio de la democracia y el gobierno. Muchos de los aspectos que prevalecen en estos Estados juegan un papel importante en el desarrollo de la política y la forma en que la sociedad tiene que convivir, por eso la relevancia de incorporar a los diversos actores y destacar su importancia para que los sistemas sigan funcionando, o bien tengan que cambiar para mejorar y superar los nuevos retos.

La búsqueda de soluciones a las relaciones entre la sociedad y el Estado obliga a la toma de decisiones a través de las políticas públicas. Lo que distingue a estas es precisamente que surgen del ejercicio de la participación de las partes interesadas para contribuir a solucionar los problemas a los que se enfrentan cotidianamente. Aunque en los pueblos indígenas los procesos de decisión y acción comunitaria no han sido considerados formalmente como políticas públicas, tienen este sentido justamente porque a través de estas decisiones y acciones públicas se solucionan los problemas comunitarios.

En el presente trabajo se analizarán estos procesos comunitarios y su importancia en un sistema político homogéneo, donde predominan las reglas impuestas por una sociedad dominante para ejercer la democracia y los derechos. Entre los aspectos que se destacan están el ejercicio de la participación ciudadana, el gobierno, y elementos abstractos como el espacio público y el ejercicio de la autoridad como sinónimo de poder público. Es a partir de estos factores que se analizarán sus implicaciones en la toma de decisiones y la implementación de medidas que contribuyen a una mejor convivencia en las sociedades indígenas.

\section{Los componentes del sistema indígena contemporáneo en México}

Aunque la unidad básica de la organización de los pueblos indígenas es la comunidad, la Constitución Política de los Estados Unidos Mexicanos reconoce al municipio, para homogeneizar la delimitación geográfica, administrativa y jurídica de la división política del territorio y la población mexicana. Sin embargo, el esquema de organización comunitaria es el mismo trátese de comunidades o municipios.

Para tener una idea más clara sobre los pueblos y comunidades indígenas mexicanos, se presentan brevemente algunas de las características y componentes de sus formas de organización. Diversos especialistas han realizado estudios sobre los principales elementos y características de los mismos, sin embargo, la misma diversidad étnica y cultural de estos pueblos, hace difícil una descripción de los patrones que engloben a este tipo de sociedades. Ávila (2003) habla de cuatro órdenes o campos interdependientes en los sistemas indígenas contemporáneos que rigen a estas comunidades:

\section{Diagrama I. Sistemas sociales indígenas: la interdependencia}

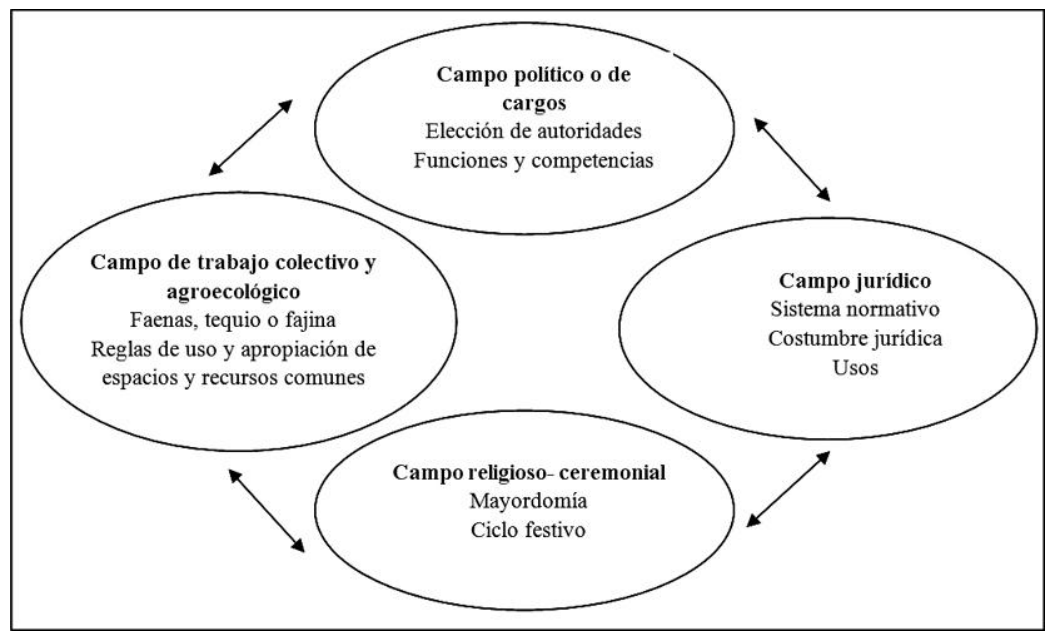

Fuente: Ávila (2003) 
Estos sistemas a su vez, conforman la costumbre comunitaria y se reflejan en las siguientes competencias: normas generales para mantener el orden interno; definición de derechos y obligaciones; definición de funciones y cargos de la autoridad, manejo, control y solución de conflictos; tipificación de delitos y sanciones y; reglamentación sobre el acceso y distribución de los recursos (Ávila, 2003: 75). Como se puede ver en el diagrama I, hay una interdependencia entre los cuatro elementos que componen este sistema comunitario

Las actividades individuales, familiares y comunitarias se rigen por principios y normas que derivan de cada uno de estos sistemas. La cosmovisión de los pueblos indígenas comprende todos los campos de la vida cotidiana y abarca desde el individuo hasta la comunidad en su conjunto. Es por eso que cualquier acción tiene una serie de implicaciones no solo hacia las personas, sino también a otros seres vivos, al medio ambiente e incluso a seres sobrenaturales.

De dicho sistema destacan dos tipos de mecanismos de cooperación, colaboración y reciprocidad intracomunitarios: aquellos que se dan a nivel de personas y familias, como la mano vuelta; $y$, aquellos que se dan en beneficio de la comunidad tales como el sistema de cargos, los trabajos comunitarios (tequio, faena o fajina) y los procesos de toma de decisión comunitaria a través de la asamblea comunitaria, como se muestran en el diagrama 2. Estos últimos son la parte central del presente análisis.

La diferencia entre ambos tipos de mecanismos es que los primeros se caracterizan porque contribuyen a ciertas situaciones del ámbito privado, como los eventos familiares (matrimonios, bautizos, fallecimientos, etc.) o personales (por ejemplo, la ayuda a alguien que está incapacitado para trabajar), que generalmente consisten en intercambios de trabajo o en especie (dinero, materiales para construcción, entre otros). Mientras que los segundos tienen están enfocados al beneficio de la comunidad en su conjunto (grupos, familias, personas no sólo de la misma comunidad, sino también aquellos que por alguna razón tienen que hacer uso de los servicios públicos o la infraestructura de esa comunidad).

\section{Diagrama 2. Estructura de cargos y los procesos de toma de decisiones comunitarias}

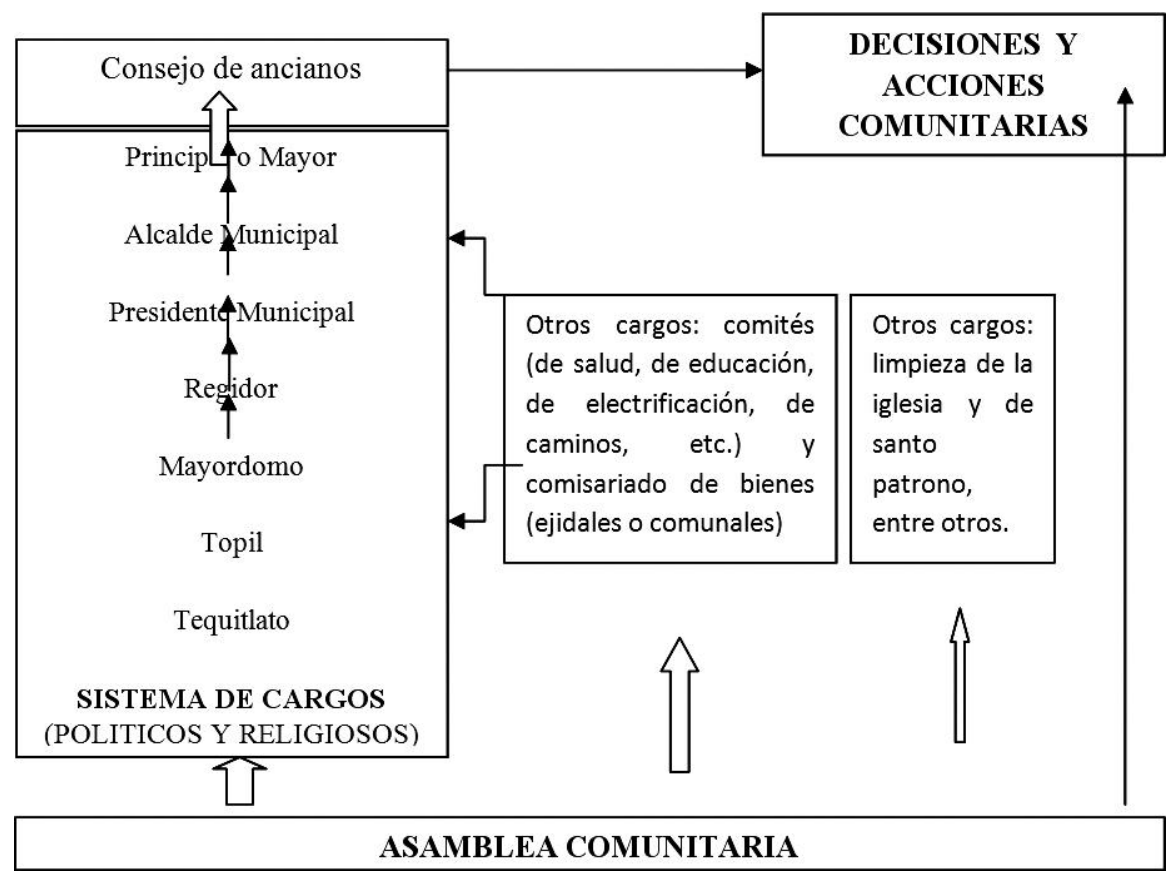

Fuente: Modificado de Gallardo (2008: 43) 
La asamblea comunitaria, las acciones y decisiones y el sistema de cargos, son las manifestaciones de lo público en estas comunidades. Esto se debe a que la concepción de estos tres elementos se basa en que constituyen instrumentos de decisión sobre los asuntos públicos de la comunidad. Sin embargo, al estar insertos en un Estado cuya base social y política es distinta, estos elementos de han visto afectados ocasionando conflictos al encontrar contraposición con las reglas de la sociedad dominante. En los siguientes apartados se analizan estos tres elementos y su importancia para el sistema de organización comunitaria.

\section{La asamblea, el trabajo y el sistema de cargos como manifestaciones de lo público en las comunidades indígenas}

Es bien sabido que en cualquier sociedad las reglas generales determinan en qué momento y bajo qué circunstancias una persona adquiere derechos y obligaciones que implican su reconocimiento como sujeto activo de la vida en sociedad. En la mayoría de los países, el origen sanguíneo o el tiempo de residencia o la mayoría de edad determinan si una persona puede ejercer sus derechos para ser considerado ciudadano de ese país y pueda intervenir en la toma de decisiones. Por ejemplo, en la constitución mexicana, se reconocen como ciudadanos mexicanos a todos aquellos que alcanzando los 18 años pueden ejercer ciertos derechos como el voto y la posibilidad de ser elegido para algún cargo público.

Sin embargo, en este mismo contexto y considerando la composición multiétnica del país, estos derechos no se cumplen a cabalidad justamente porque entre los diversos grupos étnicos originarios que componen a la sociedad mexicana, los derechos ciudadanos empiezan cuando el sujeto comienza a ejercer actividades públicas en su comunidad. De esta manera, el régimen establecido a través de los usos y costumbres para las comunidades indígenas permite $\mathrm{y}$, en ocasiones, obliga a las personas a participar en los diversos procesos comunitarios que van desde el nombramiento para desempeñar algún cargo público o bien, participar en la toma de decisiones y acciones comunitarias, como se explican con mayor detalle a continuación.

\section{La asamblea comunitaria}

La asamblea comunitaria es la base de las acciones y decisiones comunitarias, y de entre sus miembros surgen aquellos que desempeñan una función en la estructura de cargos. Aunque se ha insistido en la discriminación de los jóvenes y las mujeres en algunas comunidades, no se pueden generalizar estos casos, pues en la mayoría de las comunidades y municipios, estos sectores tienen un papel activo en los tres elementos destacados del sistema comunitario.

La participación en la asamblea comunitaria es un derecho que va acompañado del cumplimiento de las obligaciones. Una persona que ha cumplido con sus responsabilidades comunitarias, tiene derecho de participar en las asambleas, contribuir en la toma de decisiones y asumir responsabilidades a través del sistema de cargos.

No obstante, el ejercicio de la ciudadanía en estos casos coincide con lo que plantean diversos autores que han abordado el tema. Por ejemplo, desde la perspectiva aristotélica se plantea que el ciudadano "no puede definirse mejor que por su participación en la judicatura y en el poder" (Gómez, 2000: 67), es decir, a aquellos que contribuyen social y políticamente se les puede reconocer como ciudadanos porque su participación los hace acreedores a dicho reconocimiento, incluso este mismo autor lo define como alguien que "tiene parte en los honores públicos" (Ibid: 76). Este planteamiento coincide con el ejercicio de la ciudadanía en las comunidades indígenas, pues sin importar la edad, todas aquellas personas que participan activamente en las actividades y en los cargos comunitarios son reconocidas socialmente cuando se les asigna otras responsabilidades para ir ascendiendo en la estructura de cargos comunitarios.

El honor y el prestigio que se obtiene mediante el buen desempeño de los cargos anteriores otorgan mayor reconocimiento por parte de la sociedad lo cual se ve retribuido con el ascenso en la estructura que ejerce la autoridad en la comunidad. La meritocracia, es pieza clave para obtener estos beneficios. Esto difiere de las sociedades donde los cargos políticos son disputados por intereses políticos o económicos y la forma de 
hacer la política es muy distinta al que realiza donde se buscan los intereses comunes antes que los personales o de grupo.

El poder político visto desde el punto de vista de Bobbio como el que "pertenece a la categoría del poder de un hombre sobre otro" (Bobbio, 2003: 177) es diferente del que se aplica en estas comunidades indígenas, pues el poder no se ejerce como tal, sino que las personas que ocupan los cargos comunitarios tienen que ejecutar las decisiones de quienes los eligieron, es decir, ocupan el cargo para obedecer y servir a su comunidad, no para ejercer el poder sobre ella. En todo caso, si la asamblea comunitaria decide aplicar ciertas medidas, quienes detentan los cargos públicos solo llevan a cabo lo que ésta haya determinado, por ejemplo, la forma de castigar ciertos delitos o la forma en que alguien que no se acata a las normas de convivencia tiene que ser tratado para que no afecte los intereses del resto de la comunidad.

La conformación de las estructuras políticas de las comunidades indígenas se ve favorecida por dos aspectos importantes: la identidad y el espacio público. Al no haber un ejercicio de la política como en las sociedades occidentales modernas, la política comunitaria es casi imperceptible para la sociedad en su conjunto pues con ello se evitan los conflictos que la intensificación de la política genera. Gamble (2000) señala que "una concentración excesiva en la política como poder ignora las otras dimensiones: la política como identidad y la política como orden" (Ibid: 124) y enfatiza en que hace falta una política, tal como la que se realiza en estas comunidades "creando el espacio público y las normas y procedimientos bajo los que pueden considerarse autorizadas determinadas formas concretas de conocimiento" (Ibid: 143).

Las diferentes formas en que se dan los espacios comunes en la vida comunitaria se hace presente con las asambleas de todo tipo: relacionadas con la educación, con los eventos festivos, con el nombramiento de las autoridades, con la convivencia en épocas de desgracia o de las actividades agrícolas y tradicionales, etc. Estos espacios comunes son muy importantes para la toma de decisiones, el intercambio de conocimientos y la reafirmación de la identidad. Todo está lleno de simbolismos, ritos, creencias y protocolos que contribuyen al sentido de pertenencia comunitario. Por eso, por ejemplo, en las actividades cotidianas de las labores del hogar o en el campo, los padres transmiten experiencias y conocimientos a los hijos en asuntos relacionados no solo con la vida familiar sino con la vida política, social y religiosa de la comunidad, inclusive los espacios físicos y geográficos juegan un papel muy importantes, tales como los lugares de reunión como las canchas de basquetbol, los ríos, los caminos y muchos espacios que comparten los miembros de la comunidad.

Gamble indica que "el ámbito de lo público se convierte en un espacio clave para la deliberación y la determinación del interés público" (Ibid: 131). Como se planteó en el párrafo anterior, este espacio público se da no solo a través del dialogo sino la influencia de los espacios físicos donde regularmente se reúnen las personas para tomar decisiones comunitarias. Por lo tanto, la importancia de la asamblea comunitaria radica en que es el espacio público para deliberar y asumir decisiones colectivas que pretenden el logro de beneficios comunes.

\section{El sistema de cargos comunitarios}

El sistema de cargos indígena no se trata de una relación de "dominio de hombres sobre hombres", como plantea Weber (1997: 1057), y tampoco es una relación de "fuertes y débiles", como describe Bobbio (2003: 179), sino que se trata de una relación donde cada uno de los actores sabe que en el futuro o en el pasado puede o pudo estar en el papel del otro. Quienes son ciudadanos comunes tienen que ocupar en algún momento de su vida el poder político y una vez terminada esta función volverá a ser un ciudadano más con los mismos derechos y obligaciones que el resto de la sociedad. Finalmente, este ciudadano que temporalmente adquiere autoridad "tiene que vivir siempre con el mismo pueblo", en el sentido maquiavélico de El Príncipe (Maquiavelo, 1998: 39) y es mejor que no haya razones para que se haga enemigo del mismo al ser parte de él.

De alguna manera, a pesar de que no existen reglas formales, estas sociedades están constituidas sobre la base de la igualdad y semejanza entre sus ciudadanos, los cuales "estiman que deben mandar por turno" (Gómez, 2000:78), además de "tener el conocimiento y la capacidad tanto de obedecer como de mandar" (Ibid: 73). 
En el desempeño de una función pública, se tienen que reforzar los méritos, la responsabilidad y el compromiso de "servir al pueblo y no servirse de él". Esto le da a los cargos públicos un espíritu de servicio y no de obligación o de fuente de acceso al poder y al dinero, como generalmente ocurre con los cargos de elección popular en los sistemas no indígenas mexicanos. En muchas comunidades el cargo de mayordomo, con el cual las personas organizan las fiestas patronales utilizando recursos propios, es un requisito indispensable para ocupar otros cargos políticos. En este cargo, y otros como los relacionados con la limpieza del templo o de las imágenes religiosas, se da la mezcla de los aspectos religiosos con los políticos.

La fuerza pública no se aparta de estas reglas, por lo general los más jóvenes de la comunidad son quienes realizan las labores de seguridad y vigilancia del orden social, de hecho en la mayoría de los pueblos indígenas, es el segundo cargo (después del tequitlato o mensajero) que deben ocupar los jóvenes que comienzan su carrera política en la estructura de cargos comunitarios. En las comunidades que aun se rigen por el régimen de usos y costumbres puro, esto es respetado con estricta vigilancia de la comunidad. Inclusive muchas personas que emigran por motivos laborales o de estudio tienen que regresar a la comunidad para cumplir con las funciones que le son encomendados, o bien se sujetan a las sanciones que la propia asamblea decide, como ocurre en comunidades mixtecas del estado de Oaxaca, donde se concentran altos niveles de migración de sus habitantes.

La conclusión del ejercicio de este tipo de política a nivel comunitario conlleva al buen gobierno porque persigue el bien común (Bobbio, 2003) y no solo el interés político personal de quienes ejercer el poder. La ocupación de un cargo público con responsabilidades determinadas y compartidas con la asamblea, refuerza el sentido público de la función como autoridad de esa comunidad, eliminando la concentración de la capacidad y el poder para decidir sobre asuntos que competen a la sociedad en su conjunto.

\section{Las decisiones y acciones comunitarias}

Las decisiones tomadas por la asamblea en conjunto con las autoridades comunitarias, tienen el carácter de ser obligatorias para ambas partes, es decir, las autoridades no ejercen el poder en forma unilateral, vertical o centralizada sino que implementan las acciones más con base en una coordinación con la propia asamblea con los integrantes de la comunidad. Estos mecanismos asumen que los problemas que se resuelven en la asamblea son públicos, por lo tanto requieren soluciones públicas.

Por citar un ejemplo, en el año 2000 la autoridad municipal de San Pedro El Alto, una de las comunidades más pobres del estado de Oaxaca, determinó que para acabar con el problema de alcoholismo que estaba perjudicando a la mayor parte de la comunidad, debía prohibir la entrada de los proveedores de alcohol y que bebidas con este componente que se tenía en los hogares debía ser desechado para evitar continuar con este problema. La acción pasó a los hechos y las autoridades fueron a las casas a tirar el alcohol que tenían los habitantes de la comunidad y al mismo tiempo se prohibió al proveedor continuar llevando licores a la misma. En una sociedad no indígena, este hecho habría constituido una grave violación a los derechos tanto de los habitantes como del vendedor y habría llegado a resolverse ante los tribunales, sin embargo al ser una comunidad indígena donde prevalecen los usos y costumbres tradicionales, la medida no trascendió ni tuvo mayores repercusiones legales, pues finalmente el objetivo era parte del bienestar común.

Esta decisión fue implementada a partir del poder que la propia asamblea había conferido a sus autoridades para llevar a cabo dichas acciones, por lo tanto, tenían que obedecer los mandatos de manera reciproca. Por una parte, la autoridad obedece a las demandas de la asamblea y por otra, esta última obedece a las autoridades porque ellos representan el poder que ellos mismos le confirieron y que tienen que respetar como parte del cumplimiento de las normas comunitarias para mantener la armonía como sociedad.

Otra de las acciones donde se manifiesta lo público de las decisiones comunitarias es a través del trabajo comunitario, conocido como tequio, faena o fajina, dependiendo de la región o grupo étnico. La construcción y mantenimiento de la infraestructura pública (caminos, escuelas, iglesia, edificios públicos, clínicas, etc.) no es posible sin este trabajo colectivo. Incluso, aquellos que se encuentran fuera de la comunidad, realizan este tequio o faena, a través de aportaciones monetarias o en especie para contribuir al 
beneficio común. Las contribuciones al logro de estos espacios además de ser garantes y medios para el ejercicio de los derechos, reafirman los sentidos de identidad y pertenencia comunitarios.

Estos mismos espacios sirven para las actividades comunes, generalmente los auditorios y canchas municipales de basquetbol o futbol son escenarios de toma de decisiones relevantes para la comunidad. No es sólo el carácter público del espacio y la infraestructura, sino porque ahí se realizan las reuniones para tratar los asuntos comunitarios y es ahí donde se comparten experiencias y se transmiten conocimientos entre los distintos sectores de la población.

\section{Los efectos de estos mecanismos en la identidad y pertenencia comunitaria}

Las relaciones sociales no solo se dan a nivel comunidad, sino que principalmente en el ámbito personal y familiar. Rabotnikof dice que "las leyes de la casa y de los amigos pueden brindar un extraordinario sentido de pertenencia, de arraigo y de comunidad. Es una identidad que se ha de construir a partir de los habitantes de diferentes (y a veces muy inseguros) mundos privados (Rabotnikof, 2005: 308). La reciprocidad es una de las reglas informales que se ha institucionalizado en estas comunidades y la reiteración de esta reciprocidad, mediante acciones repetitivas (Arendt, 1999: 83), confirma los lazos de amistad y de confianza entre los habitantes de la comunidad. March y Olsen dicen que en "ausencia de una red de favores recíprocos carecen de valor las promesas de algún incierto apoyo futuro (March y Olsen, 1997: 54).

Por otra parte, el espacio público que se da entre gobernantes y gobernados es muy estrecho porque los ciudadanos tienen acceso de manera directa a las autoridades comunitarias por la convivencia cotidiana y lo reducido de los espacios geográficos donde se encuentran. La realización de las asambleas comunitarias conjuntamente con las autoridades evita los vacíos de poder que ocasionan las modernas formas de legislación e implementación de las políticas. Mientras tanto, en las democracias modernas basadas en la división de poderes generalmente el Congreso elabora las leyes y el Ejecutivo se encarga de implementarlas, se dan amplios espacios entre el derecho y el hecho de las políticas (Arendt, 1999; Weber, 1997), es decir, muchas veces quienes establecen el marco jurídico de las políticas desconocen las capacidades del ejecutivo para implementar adecuadamente las acciones que de ella derivan y omiten las características particulares de su población objetivo y del contexto donde se implementan. Esta homogeneización del diseño de las políticas públicas contrasta con la diversidad local que existe en los pueblos indígenas mexicanos, lo cual contribuye al fracaso de los objetivos planteados.

Rabotnikof señala que el espacio público remite a "la vigencia del Estado de derecho, al gobierno de las leyes y a las garantías publicas de la seguridad privada" (Rabotnikof, 2005: 305) y más adelante detalla y reafirma lo que se ha discutido en este trabajo, cómo a través de la historia se pueden identificar diversas "formas de orientación comunitaria, un tejido de particularismos, relaciones de reciprocidad, estrictos códigos de lealtad personal, imágenes personalizadas de la autoridad, una organización jerárquica de la vida social, rituales de respeto ostensible por la autoridad, una miríada de poderes locales, es decir, un conjunto de prácticas y de orientaciones sociales que precisamente pueden contradecir todo concepto de universalidad y formalidad de la ley y toda identidad general ciudadana. En ese sentido, la ausencia de dimensión pública de la ley se conceptualiza como el resultado de un complejo sistema de intermediación, de mando discrecional legitimado socialmente, de disposición patrimonialista, es decir, de una compleja red de relaciones en la cual la distinción básica entre la ley pública y la transacción privada resulta borrosa desde el comienzo" (Ibid: 307).

Parte de la manifestación del espacio público indígena se plasma en la legitimidad de las decisiones y el nombramiento de las autoridades de distinto orden, el cual se realiza con el levantamiento de la mano para dar a conocer que se está de acuerdo o no con estas acciones y decisiones, no es a través de tribunales electorales ni de leyes formales o expresas como rigen sus relaciones sociales. Va mas allá del sentido de legalidad, es una apropiación de las decisiones tanto por parte de quienes las proponen y obedecen, como de quienes se encargan de su cumplimiento o la ejecutan.

En ese sentido "el espacio público se concibe, entonces, como lugar de gestación de una comunidad basada en el reconocimiento mutuo, emergente de la aparición visible y manifiesta de los ciudadanos, en principio accesible a todos" (Rabotnikof, 2005:302) y no solo eso, sino que "encauza el rostro de la 
democracia, la promesa de soberanía, la demanda de sentido y la búsqueda del lugar de lo común. Su contracara sería el lado pragmático encarnado en el sistema político, en las instituciones formalizadas, en los políticos profesionales y en la política como empresa de interesados" (Ibid: 303). Esto último expresa adecuadamente las razones de por qué en los pueblos indígenas la introducción de procesos políticos ajenos han repercutido en la modificación de sus reglas tradicionales.

\section{Efectos de las políticas públicas en el sistema de organización comunitaria indígena}

Aunque March y Olsen consideran que "se da por sentado que la geografía, clima, etnicidad, ideología y religión afectan sin excepción a la política, pero no se ven afectados por ella de manera significativa” (March y Olsen, 1997: 44), en el caso de los pueblos indígenas, sí hay afectaciones de la política, sea a través de las políticas públicas o bien de los procesos políticos democráticos, en los aspectos sociales, religiosos y políticos de estas comunidades. Debido a la interrelación entre la religión y la política en los cargos y las actividades comunitarias, la influencia de las políticas paternalistas y asistencialistas, así como las ideologías de los partidos políticos han modificado los elementos del sistema comunitario al formar grupos de beneficiarios de algunos programas o grupos afines a determinadas ideologías políticas, generando divisiones sociales y exclusión de algunos miembros de la comunidad.

Los sistemas tradicionales de gobierno de los pueblos indígenas como las modernas formas de gobierno se hallan "tan repletas de símbolos, rituales, ceremonias y mitos" (March y Olsen, 1997: 49) que en la mayoría de las veces no son valorados sobre todo para el diseño e implementación de políticas públicas de los órdenes de gobierno formales (municipal, estatal y federal).

A diferencia de los sistemas donde las elecciones se realizan mediante partidos políticos y se asignan presupuestos públicos para realizar las campañas electorales, en los pueblos indígenas no hay un interés por cazar un cargo, por el contrario, muchos tienden a evadir estas responsabilidades porque implican un verdadero espíritu de servicio a la comunidad, aunque a veces sea por la fuerza, pues no hay percepciones económicas sino solo el reconocimiento y el prestigio de los demás, lo cual conlleva a seguir escalando en la estructura de cargos y para quienes llegan a los cargos más importantes como el alcalde o presidente municipal representan orgullo y será más respetado porque significa que es alguien que tuvo el valor y la capacidad de cumplir cabalmente todas las responsabilidades asignadas.

En épocas recientes, la política comunitaria se ha ido desplazando por la política de grupos, impulsadas principalmente por la injerencia de los partidos políticos que distorsionan la estructura política comunitaria creando cacicazgos que terminan interrumpiendo la cohesión social y lo que ello implica.

A pesar de las tradiciones políticas de los habitantes de estas comunidades de elegir a alguien que posee los meritos y ha fungido algún cargo público obedeciendo a los principios comunitarios, los candidatos a puestos de elección popular ajenos a estos cargos como los diputados locales o federales, senadores o gobernador, han sido elegidos por la manipulación que las estrategias partidistas deciden desde sus cúpulas. En realidad, la emisión del voto es solo para darle legalidad a estos representantes, pero no poseen este carácter porque no fueron elegidos democráticamente por quienes representan, sino fueron designados para ocupar el puesto por los grupos interesados del partido (Weber, 1997). Por eso, toda persona nombrada en estos cargos y que se apoyen en la idea de ser representantes de los pueblos indígenas o de ciertas regiones indígenas, son cuestionables pues puede estar legalmente en el cargo pero no cuentan con la legitimidad que el pueblo otorga mediante los propios mecanismos comunitarios de elección.

Actualmente en muchas comunidades indígenas, incluso las que no se rigen por el sistema de usos y costumbres, hay un ejercicio pleno de la democracia, sobre todo de la que Weber denomina plebiscitaria (Weber, 1997: 1084) pues los nombramientos de las autoridades y la toma de decisiones se realizan periódicamente y con base en la participación de todos los ciudadanos en la asamblea comunitaria. Esta periodicidad sirve para ratificar el apoyo o para manifestar el desacuerdo con las decisiones que se quieren implementar. Al mismo tiempo, son medios que otorgan legitimidad a la autoridad de quienes ocupan el poder. 
En estas comunidades la crisis del Estado no se manifiesta con el retorno de la participación de la sociedad civil en la democracia, como plantea Rabotnikof (2005), por el contrario, con la injerencia de las políticas gubernamentales y los partidos políticos, se ha ido fomentando la desaparición de la participación de la sociedad civil que es la base la organización comunitaria, pues muchas veces se fomenta el clientelismo y el divisionismo político basado en los intereses y la visión que tienen los grupos políticos nacionales que difiere mucho de la visión indígena del bienestar y el desarrollo.

\section{Conclusiones}

Las particularidades de la organización de las comunidades indígenas, son elementos que sirven de eje para la articulación de distintas reglas informales que regulan la vida social, económica, política y cultural de los mismos, a través de los mecanismos de reciprocidad y colaboración que se destacaron en este trabajo. La importancia de estos mecanismos se encuentra en que históricamente han constituido los medios tradicionales para alcanzar el bienestar comunitario como medios para la atención de las demandas y necesidades de los propios pueblos indígenas.

Sin embargo, el predominio de la reglas de la sociedad mayoritaria, aunado a la falta de reconocimiento de los derechos de estos pueblos, los ha llevado a una integración a los llamados procesos de desarrollo nacional, mediante políticas paternalistas que conciben a los indígenas como sujetos del desarrollo y no como actores que tienen su propia cosmovisión de la vida y del propio desarrollo o bienestar. La pérdida de los espacios e instrumentos tradicionales de discusión y toma de decisiones sobre los asuntos públicos han sido consecuencia de esta falta de reconocimiento y de estas políticas paternalistas.

El análisis lleva a concluir que algunos elementos de la democracia concebida desde las perspectivas no indígenas, como las políticas públicas y los procesos políticos de participación ciudadana, han afectado estos esquemas de organización y decisión comunitaria, sin embargo, habría que replantearse si el sistema comunitario indígena está muy alejado o se acerca más a la forma en que concibe democracia, pues destacan varios puntos como la cercanía de las autoridades con los gobernados, la participación activa de estos últimos en las acciones y decisiones colectivas, y los derechos van a la par con las obligaciones, que en otros ámbitos sociales y políticos, son destacables como manifestaciones naturales de un contexto plenamente democrático.

Los temas discutidos en el presente trabajo ayudan a orientar la toma de decisiones de política pública, es decir, políticas que sean resultado de los procesos que implican el diseño e implementación adecuados, no de decisiones gubernamentales que se adoptan desde una visión unilateral y alejada de la realidad, no solo de contextos particulares como el de los pueblos indígenas, sino de toda la sociedad misma porque no se está considerando lo que esta puede aportar para garantizar mejores resultados. Esto contribuiría a aprovechar mejor los recursos disponibles y se ofrecerían una mejor calidad de la democracia de la que tanto alarde se hace en las sociedades modernas.

\section{Bibliografía}

Ávila Méndez, Agustín (2003), "Sistemas sociales indígenas contemporáneos", en Los derechos de los Pueblos Indígenas. Fascículo I, Comisión Nacional de los Derechos Humanos, México D.F.

Gómez Robledo, A. (2000), Aristóteles, Política III, UNAM, México D.F.

Bobbio, Norberto (2003). Teoría General de la Política. Editorial Trotta, Madrid.

Gallardo García, David (2008), Política social y vida comunitaria. Efectos del programa oportunidades en dos comunidades mazatecas de Oaxaca (2000-2006), Tesis de Maestro en Desarrollo Regional, El Colegio de la Frontera Norte, A.C., Tijuana.

Gamble, Andrew (2000), “La política”, en Andrew Gamble, Política y destino, Siglo XXI, Madrid.

Arendt, Hannah (1999), De la historia a la acción, Paidós, Barcelona. 
Maquiavelo, Nicolás (1998), El Príncipe, Editorial Tecnos, Madrid.

March, James G. y Johan P. Olsen (1997), El redescubrimiento de las instituciones. Base organizativa de la política. F.C.E. México D. F.

Rabotnikof, Nora (2005), En busca de un lugar común. El espacio público en la teoría política contemporánea, Instituto de Investigaciones Filosóficas-UNAM, México D.F.

Sartori, Giovanni (2002). “¿Qué es la política?”, en La política. Lógica y métodos en las ciencias sociales, F.C.E., México D.F.

Weber, Max (1997), Economía y sociedad, F.C.E., México D.F.

$$
* * *
$$

Recibido: 15.02 .2012

Aceptado: 11.03.2012 